watch, is more than sufficient to scan the resonant line. This extremely small velocity range requires the apparatus to be isolated from building vibrations and the equipment was, therefore, set on a pneumatically suspended granite table.

Raghavan and Pfeiffer are optimistic, because of the importance of germanium technology and the extremely high purity and crystal perfection which can now be achieved by this technology, that the $13.3-\mathrm{keV}$ transition of ${ }^{33} \mathrm{Ge}$ will become a powerful new tool in high resolution Mössbauer spectroscopy. The experimental problems, however, are quite formidable. Since $\alpha_{\mathrm{T}}$ is so large, it would seem that a conversion electron detector which would detect the 1,100 internally converted electrons instead of, as in this paper, trying to detect the one resonant $\gamma$ photon which escapes would reduce one of the experimental difficulties. Possibly one could use a ${ }^{73} \mathrm{Ge}(\mathrm{Li})$ detector as both absorber and detector. There is no doubt, however, that ${ }^{73} \mathrm{Ge}$ Mössbauer spectroscopy does suggest many exciting possibilities to both the theoretician and experimentalist.

\section{Reindeer overgraze in South Georgia}

from our Plant Ecology Correspondent THE introduction of mammalian herbivores by man has resulted in a number of ecological problems in many parts of the world. In the British Isles the introduction of the rabbit, probably in the eleventh or twelfth centuries AD, imposed a new constraint upon the development of many vegetation types. The effezts of these animals in modifying the composition of grassland swards was ably demonstrated on the South Downs by Tansley and Adamson (J. Ecol., 13, 177; 1925) who first used exclosure as a technique for this purpose. Subsequently much work has been done on this subject, particularly since the myxomatosis epidemic of 1954 (see, for example, Thomas, $J$. Ecol., 48, 287; 1960; White, ibid., 49, $113 ; 1961)$.

The reindeer is another mammalian herbivore which has been transported to new areas by man, though not as widely as in the case of the rabbit. In 1909 eleven animals were released on the Antarctic island of South Georgia and further introduction continued until 1925 in other parts of the island. The populations have remained isolated from one another, but by 1958 the original Barff Peninsula herd had risen from 11 to 4,000 animals. Numbers have increased even further in recent years since hunting ceased in 1964. There is evidence that sheer pressure of numbers is forcing an extension of

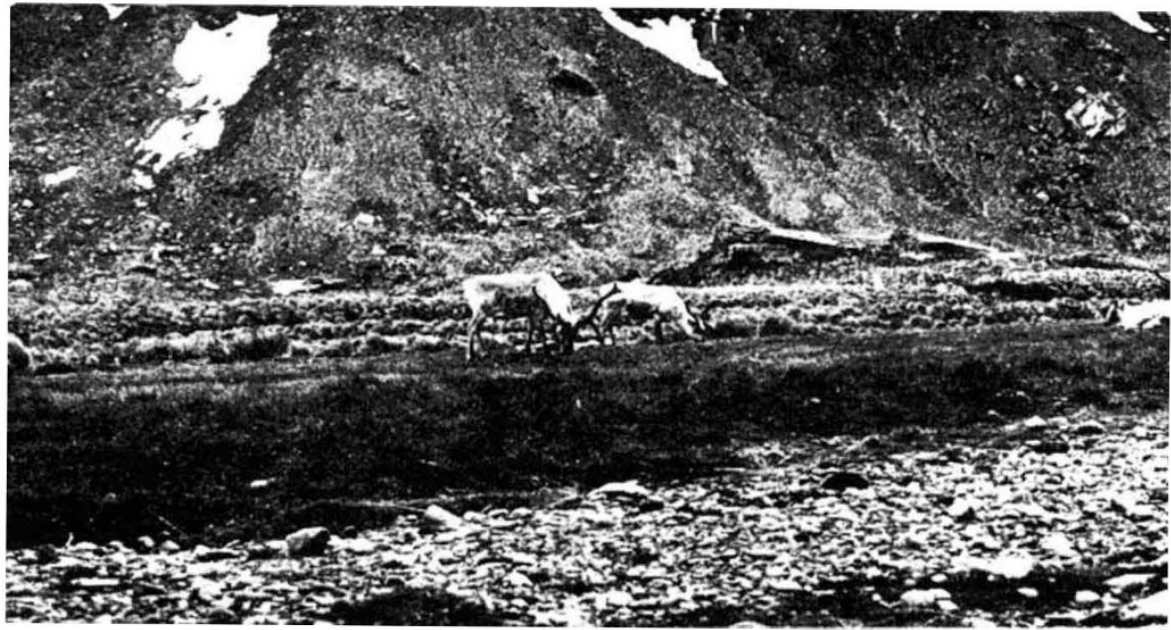

Reindeer grazing Deschampsia antarctica sward now invaded by Rostkovia magellancia in the Whale Valley, South Georgia. Photograph taken in January 1972 by P. Stone (from Lindsay, Bull. Br. Antarct. Surv., No. 35; 1973).

range despite unfavourable environmental conditions such as steep mountain slopes and glaciers with abundant crevasses.

Lindsay (Bull. Br. Antarct. Surv., No. $35,101 ; 1973)$ has reviewed the effects which high reindeer stozk densities may be having on the vegetation of South Georgia. Unfortunately, past documentation of the flora has been largely non-quantitative and this makes it difficult to be sure that vegetation is indeed changing. To supplement this anecdotal evidence concerning the past flora of the island, Lindsay makes a comparison of vegetation in grazed areas with that in similar areas which as yet have no reindeer. This method of approach also has certain disadvantages, for one can never be sure that all other factors are equal in the two sites.

Despite these difficulties, Lindsay does present evidence which suggests that the intensive grazing of reindeer is severely modifying the composition of the vegetation. Some plants, such as Acaena adscendens are little changed in overall frequency, but are reduced to a creeping, rhizomatous growth with few leafy shoots. This species was recorded in 1890 as being "richly developed" in the area. In areas of very high stock density, such as the Barff Peninsula, Acaena is almost completely eradicated; evidently the constant removal of leafy growth can weaken the species over long periods. Some species such as the grass Festuca erecta and the rush Rostkovia magellanica are apparently unpalatable and hence have increased in abundance as a result of the reindeers' selective grazing. Festuca, however, does seem to be sensitive to heavy trampling.

The most serious effects of grazing and trampling are upon the lichens. Many species abundant in the ungrazed areas are now almost or completely absent from the grazed regions. The two most abundant lichens affected are Cladonia rangiferina ("reindeer moss") and $C$. furcata. The former has vanished completely and the latter is reduced in cover abundance by a factor of ten as a result of the heavy grazing pressures. Experimental work on reindeer in the Arctic (for example, Pagau, J. Range Mgmt, 23 (2), 95; 1970) has shown a similar demise of lichens under heavy grazing and trampling pressures. Such an effect is not of widespread importance in most Arctic areas because the density of reindeer is normally far lower than in South Georgia. For example, caribou in Newfoundland are estimated to have a density of one animal per $110 \mathrm{~km}^{2}$; densities in South Georgia may locally rise as high as one animal per $0.07 \mathrm{~km}^{2}$.

The very high densities of reindeer attained in this new environment free from predation is adequate to explain the gross vegetational changes suggested by Lindsay's study. Two lessons should be learned from this work; in the first place the population levels of an introduced animal world should be strictly monitored and controlled and in the second place a more rigorous effort should be made to document the flora and fauna of areas in which such introductions are planned. Only in this way can the native biota be used as a clinical thermometer attesting the health or otherwise of a virgin community placed under an alien stress.

\section{Questioning isostasy}

from our Geomagnetism Correspondent THE observations made by the members of Pierre Bouguer's expedition to Peru between 1735 and 1745 were to lead to the discovery of one of the most important principles in geology. Bou- 